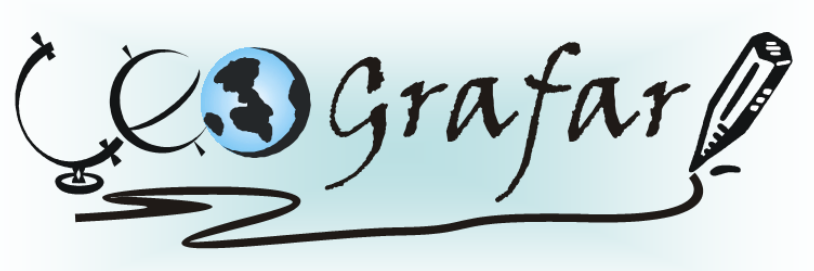

Revista Eletrônica do Programa de Pós-Graduação em Geografia - UFPR

\title{
CONTRIBUIÇÃO DA COBERTURA VEGETAL URBANA PARA A QUALIDADE AMBIENTAL E DE VIDA NO CENTRO DA CIDADE DE SÃO PAULO
}

CONTRIBUTION OF URBAN VEGETATION COVER FOR ENVIRONMENTAL AND LIFE QUALITY IN THE CENTER OF THE CITY OF SÃO PAULO

\section{(Recebido em 20-06-2016; Aceito em 22-06-2018)}

Carolina Scattolini Felix Graduada em Ciências Biológicas pela Universidade Presbiteriana Mackenzie Professora de Biologia no Cursinho Guarani da Aldeia Tekoa Pyau.

carol.scafelix@gmail.com

Oriana Aparecida Fávero Doutora em Ciências pela Universidade de São Paulo Professora na Universidade Presbiteriana Mackenzie. oafavero@mackenzie.com.br

\section{Resumo}

A alteração do meio físico, causada pela crescente aglomeração populacional, leva ao aumento dos impactos socioambientais, principalmente nas grandes cidades e metrópoles de países subdesenvolvidos e emergentes, como o Brasil. As qualidades ambiental e de vida urbana tornam-se insatisfatórias, e, para estimar o bem-estar da população, são criados índices que abordam contextos relacionados a condições econômicas, sociais e ambientais. Dessa forma, este trabalho objetivou discutir os critérios de índices para avaliar, especialmente, a qualidade de vida e verificar a contribuição da cobertura vegetal na qualidade ambiental dos distritos do centro da cidade de São Paulo (Bela Vista, Bom Retiro, Cambuci, Consolação, Liberdade, República, Santa Cecília e Sé), considerando dados demográficos e o Índice de Desenvolvimento Humano (IDH). Os dados demográficos, de cobertura vegetal e o IDH foram obtidos de mapeamentos realizados anteriormente por diversos autores. Os valores referentes à quantidade de cobertura vegetal foram comparados e analisados de acordo com o número de habitantes do Censo 2000. O Índice de Cobertura Vegetal e a distribuição da cobertura vegetal por habitante foram relacionados com o IDH, referente a cada distrito, obtido de estudo realizado em 2002 pela Secretaria do Desenvolvimento, Trabalho e Solidariedade (Prefeitura Municipal de São Paulo). Verificou-se que há grande discrepância entre os valores esperados para cada local quando são considerados aspectos demográficos, visto que distritos com maior quantidade de vegetação nem sempre apresentam a melhor distribuição desta entre seus habitantes. Da mesma forma, a maioria dos distritos que registra IDH consideravelmente maior é a que apresenta distribuição 
da cobertura vegetal por habitante mais baixa. Pode-se concluir que os índices de avaliação de qualidade de vida que não consideram devidamente a conservação da natureza nas áreas urbanas, como o IDH, não refletem adequadamente condições ambientais mínimas para uma boa qualidade de vida. Portanto, é de extrema importância que o centro de São Paulo seja considerado um dos locais prioritários para revisão de suas políticas públicas.

Palavras-chave: Centro de São Paulo, Cobertura Vegetal, Qualidade Ambiental, Índice de Desenvolvimento Humano, Qualidade de Vida.

\begin{abstract}
Changes in the physical environment caused by the increasing agglomeration leads to environmental impacts growth, especially in large towns and cities in developing and emerging countries, such as Brazil. The environmental and urban life quality becomes unsatisfactory and, to estimate the population welfare, indexes that address contexts related to economic, social and environmental conditions are created. Thus, this study aimed to discuss the indexes criteria to evaluate, especially, the quality of life and verify the contribution of vegetation cover in the environmental quality in the central districts of São Paulo, considering demographics and the Human Development Index. Demographic data, vegetation cover and the HDI were obtained through mappings carried out previously by several authors. The figures concerning the amount of vegetation cover were compared and analyzed according to the number of inhabitants in the 2000 Census. Vegetation Index and the distribution of vegetation cover per capita were related to the HDI for each district, obtained from study conducted in 2002 by the Secretaria do Desenvolvimento, Trabalho e Solidariedade (Prefeitura Municipal de São Paulo). It was found there is a large discrepancy in the expected values for each location when considering demographics, as districts with the highest amount of vegetation not always have the best distribution of this among its inhabitants. Likewise, most of the districts which records considerable HDIs shows a lower distribution of CV/hab. It can be concluded that the indices of assessing quality of life that does not properly consider the nature conservation in urban areas, such as the HDI, does not adequately reflect minimum environmental conditions for a good quality of life. So, it is extremely important that the centre of São Paulo is considered a priority for the local implementation of public policies.
\end{abstract}

Keywords: Centre of São Paulo, Vegetation Cover, Environmental Quality, Human Development Index, Quality of Life.

\title{
Introdução
}

As áreas urbanizadas são locais caracterizados por uma intensa concentração de pessoas, atividades econômicas e consequentes alterações na biosfera (PINA et al., 2010). No Brasil, os resultados do Censo Demográfico 2000 registraram uma população de quase 170 milhões de habitantes, sendo que 81\% vivia em centros urbanos (IBGE, 2001). Em contrapartida, o Censo 2010 indicou que 190.732.694 de pessoas viviam no Brasil e mostrou que a população era mais urbanizada que há 10 anos, chegando a 84\% (IBGE, 2010). Dentre as metrópoles mais populosas do Brasil está o município de São Paulo, que concentrava, no ano 2000, 10.434 .252 habitantes, numa extensão de $1.509 \mathrm{~km}^{2}$, chegando a um número correspondente a 11.253 .503 de habitantes em 2010 (INFOCIDADE, 2014). 
Pina et al. (2010) argumentam que a cidade é a real materialização da complexidade que envolve as várias relações sociais, políticas e econômicas, surgindo, assim, um espaço geográfico cada vez mais dinâmico e modificado. Os impactos causados pelo adensamento populacional e pela expansão urbana de determinada cidade atingem direta ou indiretamente a população local e, devido à quantidade de impactos e efeitos negativos sobre a esfera ambiental, esse espaço surge como uma das principais escalas de abordagem para a gestão ambiental.

Um atributo ambiental importante, mas negligenciado no planejamento do desenvolvimento das cidades é a vegetação, que não é vista, segundo Nucci (2008), como uma necessidade óbvia em áreas urbanizadas, ao contrário da terra, do ar e da água. As "áreas verdes" no espaço urbano apresentam funções ambientais importantes, mas nem sempre são valorizadas pela população e pelo setor público. Portanto, a falta de manutenção e manejo dessas áreas, bem como o planejamento inadequado, limitam o aproveitamento dos benefícios proporcionados às cidades pelas mesmas (SERAFIM, 2008).

De acordo com Fiore et al. (2007), o município de São Paulo apresenta uma difícil gestão e compreensão, devido a possível existência de "duas cidades". Uma seria a cidade formal das oportunidades, do dinamismo econômico e cultural, e a outra seria a cidade excludente, das carências na oferta de serviços públicos, da informalidade da ocupação e dos problemas sociais e ambientais.

Winkler (2011) afirma que, além do crescimento populacional sem planejamento, a concentração da distribuição dos investimentos públicos mantém a desigualdade do desenvolvimento entre os distritos da cidade de São Paulo.

O rápido crescimento das cidades é acompanhado por problemas nas redes de água tratada, na coleta e tratamento de esgoto, na pavimentação de ruas, nas galerias de água pluviais, nas áreas de lazer e áreas verdes, nos núcleos de formação educacional e profissional e nos núcleos de atendimento médico-sanitário, dificultando 0 acesso à infraestrutura para melhoria da qualidade de vida. Apesar dos avanços tecnológicos e científicos, as qualidades ambiental e de vida urbana não são satisfatórias, visto que as metrópoles concentram um grande número de pessoas e desigualdades sociais extremas, o que evidencia um desenvolvimento desigual e excludente (DORADO et al., 2011).

De acordo com Guimarães (2005), os conceitos de qualidade ambiental e qualidade de vida, muitas vezes, apresentam-se de forma equivocada e são usados como sinônimos. No entanto, a qualidade ambiental pode ser considerada um conceito mais amplo, visto que o meio ambiente propicia o desenvolvimento dos processos vitais, as relações ecológicas, a evolução dos ecossistemas naturais e construídos do planeta e a evolução das paisagens externas e internas. 
A concentração populacional e as atividades geradas pela urbanização e industrialização exercem pressões e modificam o meio ambiente, comprometendo a qualidade de vida (MONTEIRO, 1987 apud $\mathrm{NUCCl}, 2008)$.

\section{Indicadores de desenvolvimento humano e suas contribuições para a qualidade de vida urbana}

De acordo com Santos e Martins (2007 apud MASSUDA; FAVORETTO, 2010), a qualidade de vida é um tema central em todas as análises e políticas de planejamento e de gestão, principalmente no caso das cidades e regiões metropolitanas. Massuda e Favoretto (2010) argumentam que, para medir a qualidade de vida de determinado local, índices podem ser construídos abordando contextos relacionados a condições econômicas, sociais e ambientais.

Dentre os indicadores econômicos mais conhecidos, encontra-se o Produto Interno Bruto (PIB) per capita que, em meados da década de 1960, foi usado como indicador de crescimento socioeconômico pelos países (BRAGA et al., 2003; COSTA; LUSTOSA, 2007). No entanto, segundo Costa e Lustosa (2007), esse indicador não é adequado como medida de qualidade de vida e de desenvolvimento de um país, pois as dimensões (social, econômica e ambiental) devem ser captadas em conjunto.

Com o reconhecimento do caráter restritivo do PIB per capita, que considera apenas a dimensão econômica do desenvolvimento, em 1990 um novo índice é criado para avaliar o desenvolvimento dos países: o Índice de Desenvolvimento Humano (IDH) (PNUD, 2012). O IDH tem como objetivo mensurar e comparar o desenvolvimento humano das nações, sendo composto, na sua formulação clássica, por três indicadores: longevidade, educação e renda (CHEDIEK et al., 2013).

O índice é calculado anualmente e, desde 2010, é recalculado devido ao movimento de entrada e saída de países e às adaptações metodológicas. Atualmente, as três dimensões que constituem o IDH são mensuradas da seguinte forma, de acordo com PNUD (2012): uma vida longa e saudável (saúde) é medida pela expectativa de vida; o acesso ao conhecimento (educação) é medido pela média de anos de educação de adultos (número médio de anos de educação recebidos durante a vida por pessoas a partir de 25 anos) e pela expectativa de anos de escolaridade para crianças na idade de iniciar a vida escolar; e o padrão de vida (renda) é medido pela Renda Nacional Bruta (RNB) per capita expressa em poder de paridade de compra constante, em dólar, tendo 2005 como ano de referência.

Os países foram classificados em três categorias em função dessas dimensões do IDH, que varia entre zero e um, e dispostos em um ranking. A primeira categoria engloba países com baixo desenvolvimento humano (IDH $<0,500$ ); a segunda, os países de médio desenvolvimento (IDH entre 
0,500 e 0,800); e, a terceira, os países de alto desenvolvimento (IDH > 0,800) (COSTA; LUSTOSA, 2007).

Devido a sua simplicidade, fácil compreensão e forma abrangente de mensurar 0 desenvolvimento, o IDH obteve grande repercussão mundial (CHEDIEK et al., 2013). No entanto, apresenta alguns defeitos, pois tenta captar em um único número uma realidade complexa sobre desenvolvimento humano e privações de necessidades básicas (BRAGA et al., 2003). Mostra-se pouco eficiente, segundo Costa e Lustosa (2007), na representação do conjunto dos indivíduos quando em sociedades que apresentam grandes disparidades sociais, pois os valores desiguais tendem a desfigurar o quadro social.

De acordo com Chediek et al. (2013), desde 1998, no Brasil, são feitas adaptações metodológicas do IDH global para o contexto nacional, assim como em outros países, com o objetivo de adequar os indicadores às suas necessidades.

Dentre as avaliações realizadas no Brasil, com o intuito de observar disparidades e heterogeneidades entre unidades territoriais menores que o município, em 2002, a Secretaria do Desenvolvimento, Trabalho e Solidariedade (SDTS) realizou o cálculo do IDH para os 96 distritos do Município de São Paulo (SEMPLA, 2006).

O estudo teve como base os dados do Censo 2000, divulgados pelo IBGE, pela Fundação SEADE e pelas Secretarias Municipais de Finanças e de Saúde, e a metodologia seguiu indicações do IDH gerado pela PNUD, a partir de estudos realizados pela Fundação João Pinheiro e o IPEA. E, de acordo com a SDTS (2002), adaptações da fórmula geral do índice foram feitas, visto que alguns dados desagregados não estavam disponíveis para alguns dos indicadores utilizados.

Dessa forma, o PIB per capita foi substituído pelo rendimento médio do chefe do domicílio; substituiu-se o indicador de esperança de vida ao nascer pelo de mortalidade infantil, extraído da Fundação SEADE; e houve a troca dos indicadores combinados de matrícula por nível de ensino e taxa de alfabetização de adultos pela taxa de alfabetização combinada com a média de anos de estudo, ambos referentes ao chefe do domicílio (SEMPLA, 2006; SDTS, 2002).

De acordo com a Tabela 01, seis distritos apresentam IDH elevado, sendo que todos estão localizados na porção sudoeste, enquanto 52 apresentam IDH entre 0,500 e 0,799. Os extremos leste, sul, norte e a porção central no município, somando 38 distritos, possuem valor inferior a 0,499 (SEMPLA, 2006; SDTS, 2002). 
Tabela 01: Resultado do cálculo do IDH dos 96 distritos do Município de São Paulo.

\begin{tabular}{|c|c|c|c|c|c|c|c|}
\hline Distritos & Posição & IDH & População & Distritos & Posição & IDH & População \\
\hline Moema & 1 & 0,884 & 71.276 & Anhanguera & 49 & 0,528 & 38.427 \\
\hline Morumbi & 2 & 0,860 & 34.588 & Vila Matilde & 50 & $\mathbf{0 , 5 2 7}$ & 102.935 \\
\hline Jardim Paulista & 3 & $\mathbf{0 , 8 5 0}$ & 83.667 & Limão & 51 & 0,525 & 82.045 \\
\hline Pinheiros & 4 & $\mathbf{0 , 8 3 3}$ & 62.997 & Freguesia do $\mathrm{O}$ & 52 & $\mathbf{0 , 5 2 5}$ & 144.923 \\
\hline Itaim Bibi & 5 & 0,811 & 81.456 & Jaguará & 53 & 0,523 & 25.713 \\
\hline Alto de Pinheiros & 6 & $\mathbf{0 , 8 0 1}$ & 44.454 & São Lucas & 54 & 0,513 & 139.333 \\
\hline Consolação & 7 & 0,799 & 54.522 & Vila Prudente & 55 & 0,513 & 102.104 \\
\hline Campo Belo & 8 & 0,780 & 66.646 & Sacomã & 56 & 0,511 & 228.283 \\
\hline Perdizes & 9 & 0,762 & 102.445 & Raposo Tavares & 57 & 0,508 & 91.204 \\
\hline Santo Amaro & 10 & 0,759 & 60.539 & Jose Bonifácio & 58 & $\mathbf{0 , 5 0 7}$ & 107.082 \\
\hline Vila Mariana & 11 & 0,753 & 123.683 & Sé & 59 & 0,498 & 20.115 \\
\hline Butantã & 12 & 0,716 & 52.649 & São Mateus & 60 & 0,494 & 154.850 \\
\hline Bela Vista & 13 & 0,692 & 63.190 & Vila Medeiros & 61 & 0,491 & 140.564 \\
\hline Saúde & 14 & 0,686 & 118.077 & Ponte Rasa & 62 & 0,490 & 98.113 \\
\hline Santana & 15 & 0,668 & 124.654 & Tremembé & 63 & 0,489 & 163.803 \\
\hline Liberdade & 16 & 0,665 & 61.875 & Cangaiba & 64 & 0,484 & 137.442 \\
\hline Lapa & 17 & 0,661 & 60.184 & Pari & 65 & 0,484 & 14.824 \\
\hline Tatuapé & 18 & 0,657 & 79.381 & Itaquera & 66 & 0,476 & 201.512 \\
\hline Mooca & 19 & 0,655 & 63.280 & Jaçanã & 67 & 0,474 & 91.809 \\
\hline Santa Cecília & 20 & 0,654 & 71.179 & Cidade Dutra & 68 & 0,469 & 191.389 \\
\hline Vila Sonia & 21 & 0,646 & 87.379 & Vila Maria & 69 & 0,468 & 113.845 \\
\hline Campo Grande & 22 & 0,642 & 91.373 & Erm. Matarazzo & 70 & 0,464 & 106.838 \\
\hline Socorro & 23 & 0,628 & 39.097 & Cachoeirinha & 71 & 0,462 & 147.649 \\
\hline Tucuruvi & 24 & 0,618 & 99.368 & Cidade Líder & 72 & 0,460 & 116.841 \\
\hline Belém & 25 & 0,612 & 39.622 & Guaianazes & 73 & 0,458 & 98.546 \\
\hline Ipiranga & 26 & 0,594 & 98.863 & Cidade Ademar & 74 & 0,458 & 243.372 \\
\hline Mandaqui & 27 & 0,590 & 103.113 & Parque do Carmo & 75 & 0,458 & 64.067 \\
\hline Vila Andrade & 28 & $\mathbf{0 , 5 8 6}$ & 73.649 & Campo Limpo & 76 & 0,455 & 191.527 \\
\hline Cursino & 29 & 0,586 & 102.089 & Capão Redondo & 77 & 0,454 & 240.793 \\
\hline Barra Funda & 30 & $\mathbf{0 , 5 7 5}$ & 12.965 & Sao Miguel & 78 & 0,451 & 97.373 \\
\hline Jaguaré & 31 & $\mathbf{0 , 5 7 3}$ & 42.479 & Sapopemba & 79 & 0,446 & 282.239 \\
\hline Brás & 32 & $\mathbf{0 , 5 7 1}$ & 25.158 & Cidade Tiradentes & 80 & 0,446 & 190.657 \\
\hline Água Rasa & 33 & 0,570 & 85.896 & Perus & 81 & 0,442 & 70.689 \\
\hline Bom Retiro & 34 & 0,561 & 26.598 & Jardim São Luis & 82 & 0,441 & 239.161 \\
\hline Rio Pequeno & 35 & 0,561 & 111.756 & Jaraguá & 83 & 0,440 & 145.900 \\
\hline Carrão & 36 & 0,556 & 78.175 & Pedreira & 84 & 0,438 & 127.425 \\
\hline Vila Formosa & 37 & 0,555 & 93.850 & Itaim Paulista & 85 & 0,434 & 212.733 \\
\hline Vila Guilherme & 38 & 0,546 & 49.984 & Brasilândia & 86 & 0,432 & 247.328 \\
\hline Artur Alvim & 39 & 0,546 & 111.210 & Vila Curuçá & 87 & 0,431 & 146.482 \\
\hline Penha & 40 & 0,543 & 124.292 & Grajaú & 88 & 0,419 & 333.436 \\
\hline Vila Leopoldina & 41 & 0,542 & 26.870 & Jardim Helena & 89 & 0,409 & 139.106 \\
\hline São Domingos & 42 & $\mathbf{0 , 5 3 6}$ & 82.834 & Vila Jacui & 90 & 0,406 & 141.959 \\
\hline Republica & 43 & 0,534 & 47.718 & Jardim Ângela & 91 & 0,402 & 245.805 \\
\hline Cambuci & 44 & 0,534 & 28.717 & Iguatemi & 92 & 0,397 & 101.780 \\
\hline Aricanduva & 45 & 0,530 & 94.813 & Lajeado & 93 & 0,397 & 157.773 \\
\hline Casa Verde & 46 & 0,529 & 83.629 & São Rafael & 94 & 0,387 & 125.088 \\
\hline Pirituba & 47 & 0,529 & 161.796 & Parelheiros & 95 & 0,384 & 102.836 \\
\hline Jabaquara & 48 & 0,528 & 214.095 & Marsilac & 96 & 0,245 & 8.404 \\
\hline
\end{tabular}

Fonte: SDTS (2002).

Para se avaliar detalhadamente 0 desenvolvimento humano com abrangência em outras variáveis é necessária a disponibilização e a análise de outros indicadores. O PNUD compreende as deficiências do IDH global e, periodicamente, propõe metodologias que possam sinalizar algumas limitações (CHEDIEK et al., 2013).

A qualidade de vida é um conceito subjetivo e, por esse motivo, difícil de ser mensurado. Qualquer medida é redutora da realidade, porém, os índices, apesar de apresentarem informações de 
FELIX, C. S.; FÁVERO, O. A.

CONTRIBUIÇÃO DA COBERTURA VEGETAL URBANA PARA A QUALIDADE AMBIENTAL E DE VIDA NO CENTRO DA CIDADE DE SÃO PAULO

maneira simplificada, são importantes ferramentas para a sociedade estabelecer políticas públicas, sendo o bem-estar uma medida necessária no diagnóstico de vulnerabilidades socioeconômicas (FIORE et al., 2007).

\section{A importância da inclusão de parâmetros ambientais na construção dos índices}

A substituição do conceito de qualidade de vida por desenvolvimento humano gerou críticas entre os especialistas, pois a expressão baseou-se, inicialmente, em indicadores estatísticos tradicionais e objetivos, sobre índices socioeconômicos e demográficos (GUIMARÃES; DACANAL, 2006).

De acordo com Herculano (2000), o real bem-estar deve envolver, também, aspectos ambientais, pois não se pode considerar que tenha uma vida de qualidade quando se vive em locais saudáveis e bem estruturados, mas sem acesso à educação, aos serviços de saúde e à tecnologia contemporânea, e vice-versa.

A problemática ambiental passou a fazer parte da agenda oficial da região metropolitana a partir da década de 1970, quando começaram a surgir questões sobre os efeitos negativos da poluição da água e do ar (MAGLIO, 2005). Pina et al. (2010) argumenta que o grande marco na discussão ambiental em escala mundial foi a Conferência das Nações Unidas sobre o Ambiente Humano, sediada em Estocolmo na Suécia, em 1972, que surgiu da grande necessidade de se analisar as reais condições ambientais que afetavam a qualidade de vida da população.

Em 1992, no Rio de Janeiro, aconteceu a Conferência das Nações Unidas para o Meio Ambiente e o Desenvolvimento (CNUMAD), que ficou conhecida como Eco 92 ou Rio 92, e produziu a Agenda 21, a qual passou a ser exigida para cada país envolvido (PINA et al., 2010).

Como afirma Pina et al. (2010), nos municípios brasileiros houve a construção da Agenda 21 Local, focada no desenvolvimento integrado, englobando questões ambientais, sociais e econômicas. Forneceu reais possibilidades para a qualidade de vida das populações mundiais através de metas e diretrizes destinadas à sustentabilidade ambiental, sendo um importante instrumento de planejamento de políticas públicas, com envolvimento da sociedade civil e do governo, com o intuito de alcançar o desenvolvimento sustentável local.

Em 2002, ocorreu a Conferência das Nações Unidas em Joanesburgo, na África do Sul, que ficou conhecida como Rio+10 e envolveu meio ambiente, sociedade e economia, com o propósito de se avaliar os resultados atingidos, em relação às propostas da Eco 92, pelos países envolvidos (GONÇALVES, 2004 apud PINA et al., 2010). 
De acordo com Costa e Lustosa (2007), a partir da Eco 92, diversos indicadores e índices foram propostos e inseridos no contexto das políticas públicas e na agenda de políticos e diplomatas, para avaliação do progresso dos países em direção ao desenvolvimento sustentável. Os indicadores e índices de sustentabilidade são fatores que permitem que os países avaliem seus progressos em relação à gestão ambiental e ao desenvolvimento sustentável ou ao bem-estar humano e do ecossistema.

Existem diversas propostas de indicadores alternativos de desenvolvimento do tipo índice ou sintético, em que as variáveis incluídas nos cálculos são ambientais e não somente socioeconômicas. Dentre elas destacam-se:

- Índice do Planeta Vivo: agrega três indicadores (área de cobertura de florestas naturais, espécies de água doce e espécies marinhas) e pode ser aplicado para países e regiões (COSTA; LUSTOSA, 2007);

- Bem-Estar Nacional Líquido: criado para a correção da renda nacional, feita através da subtração de investimentos que não geram bem-estar e acréscimos de serviços governamentais, bens duráveis e atividades domésticas. Além de incluir os efeitos da urbanização, o tempo de lazer e a poluição ambiental, é calculado um custo de restauração do padrão exigido (COSTA; LUSTOSA, 2007);

- Índice de Bem-Estar Econômico Sustentável: agregou medidas convencionais (distribuição de renda, trabalho doméstico, poluição do ar e da água, degradação do solo agrícola e perda de recursos naturais) para mostrar que não há um desenvolvimento adequado das sociedades quando seus ecossistemas declinam. Porém, considera o bem-estar econômico baseando-se somente no consumo material sustentável e não considera o aspecto socioambiental de forma abrangente o suficiente para caracterizar a sua sustentabilidade (COSTA; LUSTOSA, 2007);

- Pegada Ecológica: permite identificar as relações de dependência entre o ser humano, suas atividades e os recursos naturais necessários para a sua manutenção, monitorando aspectos da melhoria de qualidade de vida de uma população no contexto dos limites ecológicos (COSTA; LUSTOSA, 2007);

- Índice de Progresso Genuíno: criado como proposta de substituição do PIB, com o objetivo de mensurar o progresso das nações a partir de parâmetros de bem-estar e meio ambiente. Subtrai, em seu cálculo, custos decorrentes de alguns fatores (criminalidade, poluição, degradação ambiental e comprometimento dos recursos e sistemas naturais) e acresce itens como os trabalhos doméstico e voluntário (LOUETTE, 2009). 
- Painel de Controle de Sustentabilidade: é caracterizado por ser uma ferramenta que aponta as dimensões do desenvolvimento (ecológica, econômica, social e institucional) e o grau de sustentabilidade de cada uma delas, através de um sistema agregado de indicadores que utiliza pontos de 1 a 1.000 e cores que representam as dimensões de determinado país (MARTINS et al., 2006);

- Índice de Sustentabilidade Ambiental: criado com o objetivo de comparar a habilidade na proteção do meio ambiente nos períodos atuais e nas próximas décadas, como uma alternativa ao PIB e ao IDH na avaliação do progresso de um país (MARTINS et al., 2006). Segundo Costa e Lustosa (2007), apesar do índice conter inúmeras variáveis ambientais, ser de fácil interpretação e permitir a comparabilidade internacional, utiliza a mesma ponderação para todas as variáveis;

- Indicadores de Desenvolvimento Sustentável do Brasil: a construção dos indicadores faz parte do conjunto de esforços internacionais para concretização das ideias e dos princípios formulados na Rio 92, contendo informações sobre a realidade brasileira a partir da integração das dimensões social, ambiental, econômica e institucional (LOUETTE, 2009). Completou uma década em 2012, ano em que foi realizada, no Brasil, a Conferência das Nações Unidas sobre Desenvolvimento Sustentável (Rio+20), com novas soluções referentes aos problemas ambientais, econômicos e sociais, através da implementação de estratégias acompanhadas e avaliadas por indicadores capazes de captar supostos desafios durante a transição para um desenvolvimento sustentável (IBGE, 2012);

- Felicidade Interna Bruta: considera que a felicidade é um direito fundamental de todos os cidadãos, sendo vista como o centro do desenvolvimento (ALVIM, 2011). Segundo Pecnnock (2010 apud ALVIM, 2011), o conceito tem abordagens econômicas, sociais e ambientais, incorporando questões relacionadas ao bem-estar, à cultura e à governança. Vialli (2012) comenta que o conceito surgiu novamente como um dos temas da Rio+20, levando em consideração 9 eixos que se desdobram em 33 indicadores;

- Índice de Riqueza Inclusiva: lançado na Rio+20, pelo Programa Internacional de Dimensões Humanas sobre Mudança Ambiental Global, e organizado pela Universidade das Nações Unidas e pelo Programa das Nações Unidas para o Meio Ambiente (PNUMA). $O$ indicador foi divulgado no Relatório de Riqueza Inclusiva, em 2012, o qual observou as mudanças na riqueza inclusiva em 20 países, que, juntos, representariam quase três quartos do PIB mundial, de 1990 a 2008. O índice mostra aos governos a verdadeira situação da riqueza das suas nações e a sustentabilidade de seu crescimento (PNUMA, 2012).

Braga et al. (2003) considera que a dimensão ambiental do desenvolvimento é composta por uma série de aspectos, o que dificulta a busca por um índice sintético de desenvolvimento sustentável. A mensuração da sustentabilidade precisa de um grande número de informações e da integração de 
diversas áreas do conhecimento, fato que tornaria os indicadores complexos no momento em que as realidades fossem resumidas ao público.

Dorado et al. (2011) afirma que há a necessidade de elaboração de um planejamento para se fazer uma análise que considere as características físicas, biológicas e socioeconômicas da área em estudo, bem como o reconhecimento dessa área para a realização de projetos de atuação local.

Para um planejamento urbano adequado e melhor ordenamento dos espaços urbanos, é necessário, de acordo com Cavalheiro e Del Picchia (1992), que haja um enfoque no nível da "grande paisagem" e do planejamento das cidades, contribuindo para a integração da natureza com a cultura do ser humano.

\section{Importância da Conservação da Vegetação Urbana nas cidades para melhoria das qualidades ambiental e de vida da população}

A sustentabilidade do aglomerado urbano pode ser relacionada com algumas variáveis, como a forma de ocupação do território, a disponibilidade de serviços, a descarga de resíduos, o grau de mobilidade da população e atendimento às necessidades por moradia, a qualidade dos espaços públicos, dentre outros. Esse processo de ocupação da cidade pode gerar situações de difícil reversão como a impermeabilização excessiva do solo, enchentes, erosão e supressão de áreas com cobertura vegetal natural (TAKIYA, 2002).

No processo de urbanização, há um aumento da impermeabilização por conta da ocupação do solo por concreto e, de acordo com Nucci (2008), isso faz com que os corpos d'água e os espaços livres vegetados sejam reduzidos. A superfície de concreto, que apresenta alta capacidade térmica, é aumentada devido à verticalização, levando à diminuição da evaporação, ao aumento da rugosidade e da capacidade térmica da área, o que contribui para a formação de "ilhas de calor", intensificando os problemas de poluição no ambiente urbano. Segundo Eliers (1992 apud NUCCI, 2008), a maneira como o solo é ocupado pode ter influência específica no clima local.

Serafim (2008) afirma que as "áreas verdes" podem ser consideradas atributos para a melhoria dos impactos e podem indicar o grau da qualidade de vida da população urbana, de acordo com a distribuição da vegetação.

Lombardo (1990 apud NUCCl, 2008) argumenta que a vegetação influencia positivamente a qualidade de vida da população urbana em relação:

- à composição atmosférica, por meio da fixação de poeiras e materiais residuais, da depuração bacteriana e de outros micro-organismos, da reciclagem de gases através dos mecanismos fotossintéticos e fixação de gases tóxicos; 
- ao equilíbrio solo-clima-vegetação, suavizando temperaturas extremas através da radiação solar, conservando a umidade do solo, atenuando a temperatura, reduzindo a velocidade dos ventos, mantendo a permeabilidade e a fertilidade do solo, fornecendo abrigo à fauna existente e influenciando o balanço térmico;

- ao nível de ruído, através do amortecimento dos resíduos de fundo sonoro contínuo e descontínuo de caráter estridente, que ocorrem nas grandes cidades.

Apesar de tantos benefícios, Batista (2002) argumenta que existe grande descaso com a arborização urbana, principalmente pelo setor público. Há falta de planejamento técnico, de acompanhamento de plantio e condução adequados, assim como de laudos técnicos incorretos, em conjunto com as condições de trabalho inadequadas ao exercício da profissão. Todos esses conflitos colocam as árvores como um empecilho na cidade e, para amenizar essa situação, são necessárias medidas que envolvam a promoção de plantios, manutenção e conservação do verde urbano, contribuindo para a melhoria da qualidade do ambiente.

A cobertura vegetal é um parâmetro de suma importância no planejamento e gestão ambiental das cidades, visto que está sujeita a diferentes níveis de vulnerabilidade ao longo do tempo (SERAFIM, 2008). No entanto, a preocupação de quem planeja continua centrada nas características socioeconômicas e não tem dado atenção à qualidade de um ambiente composto por vegetação (LOBODA; DE ANGELIS, 2005).

De acordo com Maglio (2005), a cidade de São Paulo apresenta um déficit significativo de espaços públicos e vegetação e, segundo levantamentos da Secretaria Municipal do Verde e do Meio Ambiente em 2001, cerca de três milhões de pessoas não usufruem de nenhuma área verde ou lazer, sendo que no período entre 1986 e 1999, houve perda de cerca de 30\% da cobertura vegetal, principalmente nas áreas mais periféricas.

Cavalheiro et al. (1999) e Nucci (2008) argumentaram a existência de um índice de $12 \mathrm{~m}^{2}$ de "área verde" por habitante, o qual poderia ser considerado o ideal e que teria sido desenvolvido pela Organização Mundial da Saúde (OMS), Organização das Nações Unidas (ONU), Organização das Nações Unidas para Agricultura e Alimentação (FAO) e PNUMA. Porém, esse valor pode ser considerado inadequado, já que este se refere somente a parques de bairro e distritais ou setoriais, excluindo-se os parques de vizinhança, unidades de conservação, parques regionais e outros.

Para diferenciar "área verde" de "cobertura vegetal", é necessária a compreensão da definição desses termos, evitando, dessa forma, falsas interpretações e um uso político incorreto. $O$ cálculo do índice de cobertura vegetal por habitante é diferente do cálculo do índice de área verde, pois considera todas as manchas de vegetação (NUCCl, 2008). 
Para um balanço térmico adequado em áreas urbanas, o mais recomendável seria um índice de cobertura vegetal na faixa de $30 \%$, sendo que áreas com um índice de arborização inferior a $5 \%$ determinam características semelhantes às de um deserto (OKE, 1973 apud $\mathrm{NUCCl}, 2008$ ).

A obtenção do Índice de Cobertura Vegetal (ICV) pode ser realizada por meio do mapeamento de toda a cobertura vegetal de um bairro ou cidade, e posterior quantificação em $\mathrm{m}^{2}$ ou $\mathrm{km}^{2}$, chegandose à porcentagem existente nessas áreas (NUCCl, 2008).

A partir dos dados referentes à quantidade de cobertura vegetal e ao número de habitantes de um determinado local, chega-se a um índice correspondente à cobertura vegetal por habitante (CV/hab.). Sendo o foco deste trabalho, tem o intuito de analisar a forma como a vegetação encontrase distribuída entre a população e a sua contribuição para a qualidade ambiental e de vida dos habitantes em áreas urbanizadas.

\section{Estudos de Cobertura Vegetal e Avaliação da Qualidade Ambiental Urbana}

Os procedimentos para a realização do levantamento da cobertura vegetal em áreas urbanas são diversos. De acordo com Luchiari (2001), estes podem ser feitos por meio de trabalhos de campo, análise de cartas e plantas topográficas em escala grande, interpretação de fotografias aéreas e análise de imagens obtidas no nível orbital. E, ainda, existem sistemas sensores como os fotográficos, de varredura e os radares, os quais são projetados para o fornecimento de dados referentes às porções da superfície terrestre, através da radiação eletromagnética usada como fonte de energia.

A cobertura vegetal é definida por Nucci (2008) como manchas de vegetação visíveis a olho nu em foto aérea, na escala 1:10.000, impondo um limite do que pode ser visualizado e mapeado.

O mapeamento da cobertura vegetal pode ser realizado por meio do levantamento e obtenção de fotos aéreas em escalas maiores (pelo menos 1:10.000), com interpretação a olho nu e identificação dos focos de vegetação visíveis. Após a obtenção das fotos aéreas, é feita a composição do mosaico da área de estudo e, então, através de um método chamado overlay, as áreas vegetadas são demarcadas com a utilização de papel acetato e caneta de retroprojeção. Em seguida é feita a quantificação da área total, e das áreas com cobertura vegetal, com o auxílio de um papel vegetal milimetrado (LOPES; FÁVERO, 2006).

Além da quantificação, outra forma de avaliar as condições da cobertura vegetal é por meio de sua configuração ou da distribuição das manchas de vegetação, mapeadas pelo método de overlay. Jim (1989) elaborou um estudo chamado Tree-capony cover, no qual apresentou uma proposta pioneira para classificar as diferentes configurações de manchas da cobertura vegetal arbórea para a cidade de Hong Kong, conforme mostra a Figura 01. 
Figura 01: Classificação da cobertura vegetal em categorias e subcategorias

1. ISOLATED

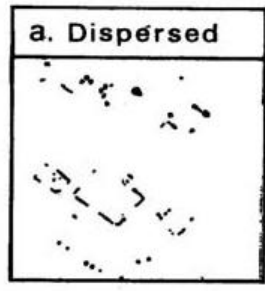

2. LINEAR

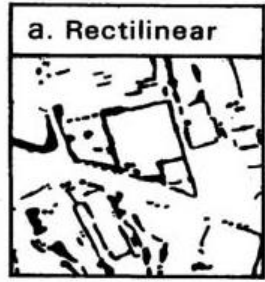

3. CONNECTED

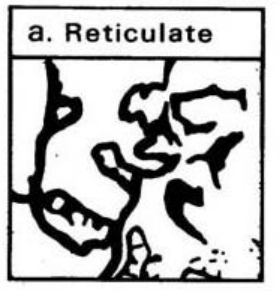

Tree canopy cover
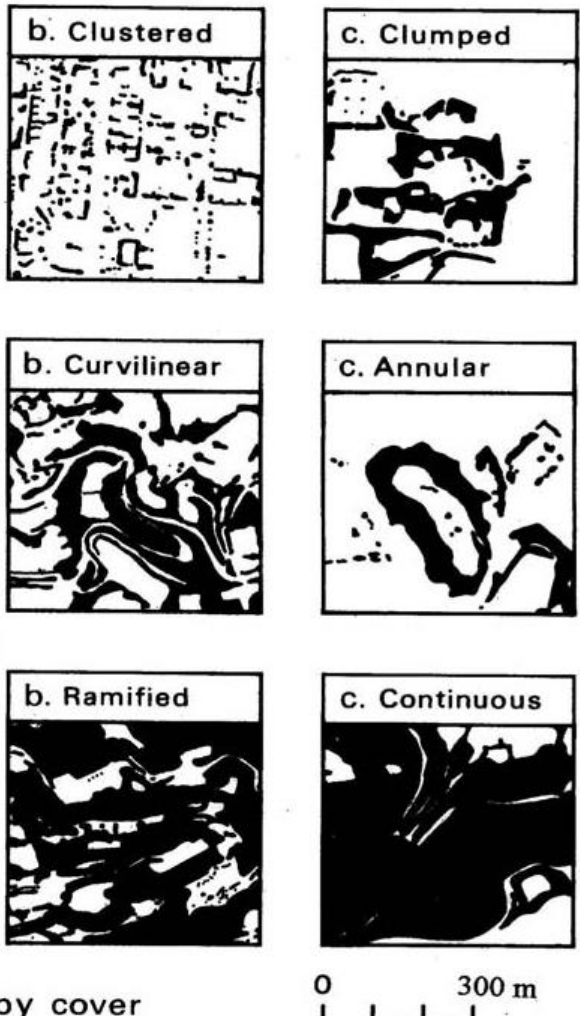

Fonte: JIM (1989, p. 218)

A distribuição, conectividade e contiguidade desta cobertura serviram de base para a análise e classificação das manchas de vegetação em três categorias principais (JIM, 1989):

- Isolated: predominante em locais edificados, pavimentados e com ruas e superfícies impermeabilizadas, onde são observados pequenos focos de vegetação; essa categoria, assim como as outras, encontra-se dividida em três subcategorias:

- Dispersed (pequenas manchas isoladas e desconectadas entre si), Clustered (pequenos grupos de árvores) e Clumped (agregações de manchas arbóreas);

- Linear. justaposição de árvores em uma direção dominante, em diversos arranjos; suas subcategorias incluem: Rectilinear (alinhamento estreito de árvores ao longo das calçadas e periferia de lotes), Curvilinear (segmentos largos, com vertentes naturais ou modificadas, adjacentes às ruas) e Annular (manchas que formam um anel ao redor de morros e montanhas);

- Connected: formado por uma ampla vegetação com alto grau de conectividade e continuidade, e subdivide-se em: Reticulate (vegetação em redes alongadas que atravessa interstícios de vertentes não urbanizadas), Ramified (área constituída com mais de 50\% de cobertura vegetal) e Continuous 
(área constituída com mais de $75 \%$ de cobertura vegetal, que é caracterizada pela constituição de florestas na periferia de locais pouco urbanizados).

Vários estudos se basearam nessa metodologia, com o propósito de mapear, classificar e quantificar a cobertura vegetal das cidades para avaliar a qualidade ambiental destes locais e propor medidas para sua melhoria. Dentre eles, destacam-se, para este trabalho, os realizados no centro de São Paulo, especialmente nos distritos administrados pela Subprefeitura da Sé, que correspondem a: Sé, República, Santa Cecília, Bom Retiro, Liberdade, Bela Vista, Consolação e Cambuci.

De acordo com os estudos, a cobertura vegetal do centro de São Paulo, apresenta configuração predominantemente Isolated, categoria proposta por Jim (1989), considerando que, na maior parte dos distritos, a vegetação concentra-se em manchas pequenas e está irregularmente distribuída, sendo fragmentada e desconectada ou descontínua, como mostram os mapas de Cobertura Vegetal do Distrito da Sé e da Consolação nas Figuras 02 e 03, por exemplo.

Nestes estudos ainda se destaca a quantificação da cobertura vegetal em relação à área total do distrito (ICV), que possibilitou verificar que, em média, os distritos do centro apresentam ICV de 10,7\%. Porém, na Tabela 02, pode-se notar que o distrito da Consolação é um desvio significativo, apresentando ICV de quase $27 \%$, em contraste com os demais distritos nos quais foram verificados ICVs abaixo de 10\% (LOPES; FÁVERO, 2006; NUCCI, 2008; ADAS; FÁVERO, 2008; NUNES et al., 2008; BUITRON; FÁVERO, 2009; LIANG, 2009; MALDONADO; FÁVERO, 2011; GOMES; FÁVERO, 2013). 
Figura 02: Mapa da Cobertura Vegetal do Distrito da Sé

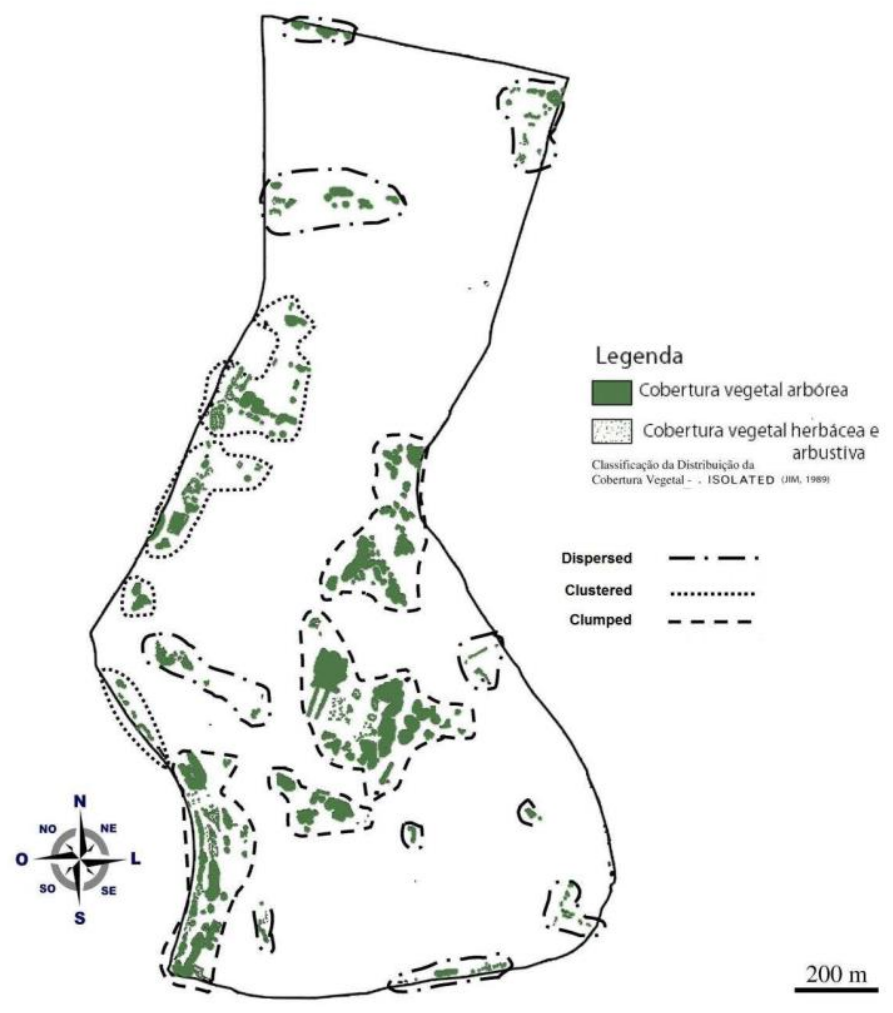

Fonte: NUNES et al. (2008).

Figura 03: Mapa da Cobertura Vegetal do Distrito da Consolação

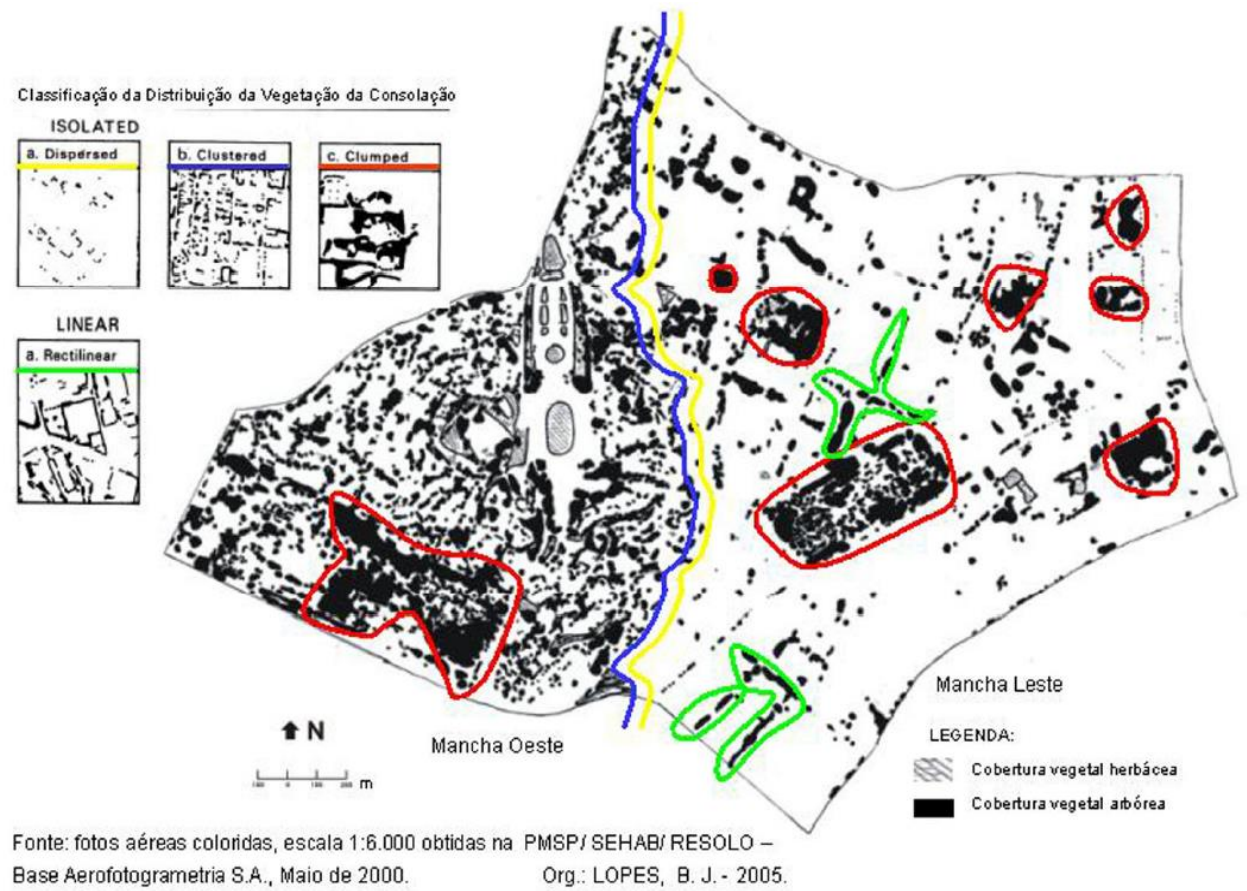

Fonte: LOPES; FÁVERO (2006). 
É importante ressaltar que os estudos supracitados só foram comparáveis, pois utilizaram as mesmas metodologias de mapeamento e quantificação da cobertura vegetal, bem como os mesmos produtos de sensoriamento remoto (fotos aéreas de 2000, na escala 1:6.000, obtidas com a Prefeitura de São Paulo) e mapeamento final na mesma escala (1:10.000).

Tabela 02: Índices de Cobertura Vegetal (ICV) obtidos dos estudos de cobertura vegetal dos Distritos do Centro de São Paulo (SP)

\begin{tabular}{ccc}
\hline Citação do Estudo & Localidade & ICV (\%) \\
\hline Gomes e Fávero (2013) & Distrito de Cambuci & 8.64 \\
\hline Maldonado e Fávero (2011) & Distrito do Bom Retiro & 9.71 \\
\hline Liang (2009) & Distrito da Liberdade & 8.08 \\
\hline Buitron e Fávero (2009) & Distrito da Bela Vista & 9.02 \\
\hline Nunes et al. (2008) & Distrito da Sé & 6.97 \\
\hline Nucci (2008) & Distrito da Santa Cecília & 7.00 \\
\hline Adas e Fávero (2008) & Distrito da República & 8.76 \\
\hline Lopes e Fávero (2006) & Distrito da Consolação & 26.90 \\
\hline
\end{tabular}

Fonte: GOMES; FÁVERO (2013, p. 188).

Com base em estudos realizados nos distritos do centro de São Paulo, este trabalho objetivou discutir os critérios de índices para avaliar, especialmente, a qualidade de vida e verificar a contribuição da cobertura vegetal na qualidade ambiental dos distritos do centro da cidade de São Paulo, considerando dados demográficos e o Índice de Desenvolvimento Humano (IDH).

\section{Método}

A área estudada foi a dos distritos do centro da cidade de São Paulo (Bela Vista, Bom Retiro, Cambuci, Consolação, Liberdade, República, Santa Cecília e Sé), que se encontra sob administração da Subprefeitura da Sé, apresentada com mais detalhes na Figura 04.

O local, observado na Figura 04, é delimitado da seguinte maneira: ao Norte está a Avenida Marginal Tietê Expressa; ao Sul a Rua Coronel Diogo e os cruzamentos com a Avenida Lacerda Franco e Rua Ximbó; à Leste a Avenida do Estado; ao Nordeste a Avenida Cruzeiro do Sul; ao Sudeste a Rua da Mooca, cruzando com a Linha Ferroviária na altura da estação Bresser-Mooca e parte das 
Avenidas do Estado e Dom Pedro I; a Oeste a Avenida Pacaembu em cruzamento com a Avenida Dr. Arnaldo; ao Noroeste a Avenida Dr. Abrahão Ribeiro; ao Sudoeste a Avenida Paulista e a Linha Ferroviária na altura das estações Clínicas, Consolação, Trianon Masp e Brigadeiro Faria Lima, cruzando com a Avenida Vinte e Três de Maio.

Figura 04: Mapa da delimitação da Subprefeitura da Sé e seus respectivos Distritos

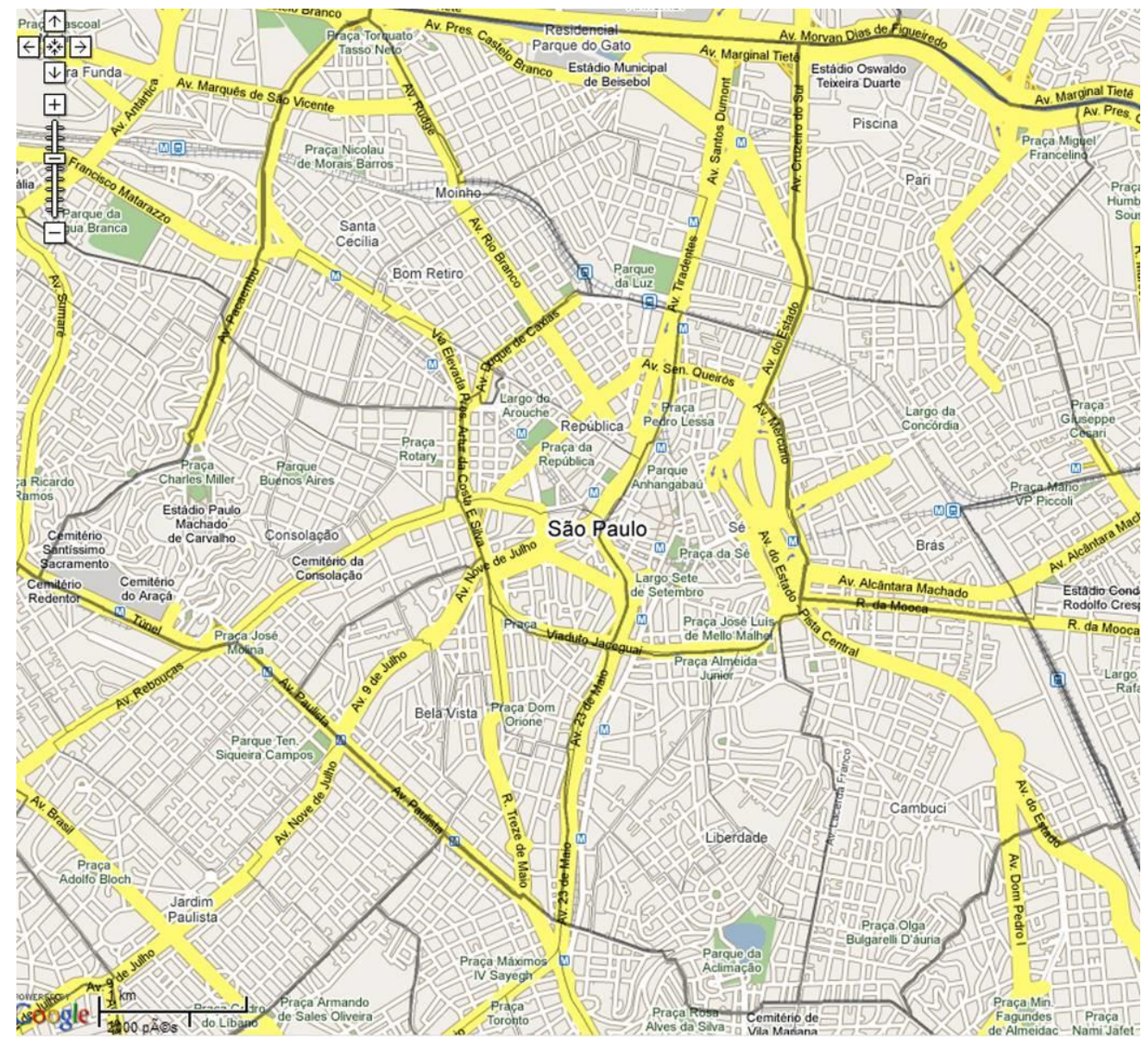

Fonte: IBGE, Censo 2010. (Disponível em:

(http://www.cens02010.ibge.gov.br/sinopseporsetores/?nivel=st), data de acesso: 22 de abril de 2014). Org.: FÁVERO (2014)

De acordo com os dados da Infocidade (2014), a Subprefeitura da Sé apresentava, no ano 2000, uma população de 373.914 habitantes, chegando a 431.106, em 2010, em uma área de 26,20 $\mathrm{km}^{2}$, sendo, portanto, sua densidade demográfica de 16,45 hab./km².

Inicialmente foram realizados levantamentos bibliográficos de trabalhos relacionados com 0 objeto de estudo, para caracterização dos critérios e respectivos parâmetros de avaliação da qualidade ambiental e de vida urbana com base na vegetação e aspectos socioeconômicos. 
Os dados referentes ao Índice de Cobertura Vegetal e à área dos distritos da Subprefeitura da Sé (centro de São Paulo) foram obtidos, principalmente, de estudos publicados a partir de Trabalhos de Conclusão de Curso realizados na Universidade Presbiteriana Mackenzie, para a obtenção do título de Bacharel em Ciências Biológicas, com exceção dos distritos de Santa Cecília e da Sé:

$\checkmark$ Distrito de Santa Cecília (NUCCl, 2008);

$\checkmark$ Distrito da Consolação (LOPES; FÁVERO, 2006);

$\checkmark$ Distrito da Bela Vista (BUITRON; FÁVERO, 2009);

$\checkmark$ Distrito da República (ADAS; FÁVERO, 2008);

$\checkmark$ Distrito da Sé (NUNES et al., 2008);

$\checkmark$ Distrito da Liberdade (LIANG, 2009);

$\checkmark$ Distrito do Bom Retiro (MALDONADO; FÁVERO, 2011);

$\checkmark$ Distrito do Cambuci (GOMES; FÁVERO, 2013).

Todos os distritos foram mapeados com o mesmo produto de sensoriamento remoto, com fotos aéreas pertencentes ao ano 2000, obtidas na Secretaria da Habitação da Prefeitura de São Paulo (SEHAB), com exceção do distrito de Santa Cecília, que foi mapeado a partir de fotos aéreas de 1989. Foi utilizado, também, o mesmo método de quantificação da cobertura vegetal (overlay), tornando os estudos comparáveis.

A partir da obtenção dos dados de cada local, foi realizada uma comparação entre os valores obtidos e posterior análise da quantidade de cobertura vegetal total por habitante, em $\mathrm{m}^{2}$, com o intuito de avaliar a qualidade ambiental das áreas correspondentes.

Estabeleceu-se uma relação entre os diferentes índices de cobertura vegetal com o IDH de cada distrito destacado na Tabela 01, visto que é o índice mais utilizado para estabelecer o grau de qualidade de vida da população, sem considerar os aspectos ambientais em seu cálculo.

O valor correspondente ao IDH distrital foi obtido do estudo realizado, em 2002, pela Secretaria do Desenvolvimento, Trabalho e Solidariedade, com dados advindos do Censo 2000, divulgados pelo IBGE, pela Fundação SEADE e pelas Secretarias Municipais de Finanças e de Saúde. A metodologia seguiu indicações do IDH gerado pelo PNUD, a partir de estudos realizados pela Fundação João Pinheiro e o IPEA, com algumas adaptações.

\section{Resultados e discussões}

Os dados contidos na Tabela 03 pertencem aos distritos do centro de São Paulo e se referem à demografia, à quantificação e distribuição da cobertura vegetal entre a população domiciliada e ao IDH distrital. Nela são apresentados os gradientes referentes ao Índice de Cobertura Vegetal (ICV em \% da 
área), à Cobertura Vegetal por Habitante (CV/hab. em m²/hab.) e ao IDH dos distritos, sendo que os destacados em vermelho são considerados baixos, os destacados em amarelo são considerados médios e os azuis são considerados altos, de acordo com os valores estabelecidos para cada índice.

Para o ICV foram considerados valores de acordo com o estipulado por Oke (1973 apud NUCCI, 2008), sendo que quanto mais próximo de $30 \%$, melhor e mais alto é o índice, e, quanto mais próximo de $5 \%$ ou inferior a isto, mais baixo é o índice, caracterizando locais considerados "desertos florísticos".

Para a CV/hab. foi utilizado o valor referente ao Índice de Área Verde (IAV) por habitante, que, apesar de controvertido, é usado como referência pela Lei Estadual $n^{\circ} 13.580 / 2009$, a qual instituiu 0 Programa Permanente de Ampliação das Áreas Verdes Arborizadas Urbanas, com 0 intuito de mitigação da formação de "ilhas de calor" e da poluição sonora e na conservação da biodiversidade, através de um IAV de $12 \mathrm{~m}^{2}$ por habitante (ASSEMBLEIA LEGISLATIVA DO ESTADO DE SÃO PAULO, 2009). Portanto, índices que ultrapassam esse valor podem ser considerados altos e, os que se afastam, são considerados baixos.

E para o IDH, os valores considerados foram os referentes ao trabalho desenvolvido pela Secretaria do Desenvolvimento, Trabalho e Solidariedade em 2002. Os valores abaixo de 0,500 revelam um índice baixo, valores entre 0,500-0,800 são considerados médios, e, quando acima de 0,800, o índice é considerado alto.

Analisando brevemente a Tabela 03, nota-se que os distritos do centro de São Paulo apresentam densidades demográficas consideravelmente altas, principalmente o distrito da Bela Vista (258 hab./ha), de Santa Cecília (197 hab./ha), da República (167 hab./ha), da Liberdade (162 hab./ha) e da Consolação (105 hab./ha), em contraposição a ICVs inferiores a 10\% da área, com exceção do distrito da Consolação (ICV de 26,89\%).

Segundo Oke (1973 apud NUCCl, 2008) um ICV recomendado para amenização de "ilhas de calor" seria de cerca de $30 \%$, e todos os distritos apresentam cobertura vegetal inferior a isto, com exceção do distrito da Consolação. Para Nucci (2008), a qualidade ambiental de todos os distritos, considerando tanto o ICV quanto a CV/hab., está comprometida, assim como a qualidade de vida. Locais com ICV abaixo de 5\% apresentam qualidade ambiental bem inferior à desejável, porém, não se pode afirmar que os que apresentam ICV superior a 5\% apresentam qualidade ambiental aceitável, pois devem ser consideradas outras variáveis conjuntamente.

O ICV do distrito da Consolação, destacado em azul na Tabela 03, é o único que se aproxima do valor esperado de $30 \%$. Os outros sete distritos estão destacados em amarelo e possuem valor intermediário, apesar de estarem bem distantes do valor esperado. Nenhum distrito apresentou valor inferior a $5 \%$. 
Ao considerar a população em relação à quantidade de cobertura vegetal disponível, com a criação de um índice de CV/hab., foi possível observar as discrepâncias existentes entre ICV e CV/hab. nos distritos.

Verificando-se a CV/hab., a situação mostra-se ainda mais crítica, visto que os números são, em sua maioria, inferiores à $12 \mathrm{~m}^{2} / \mathrm{hab}$., salvo o distrito do Bom Retiro (17,14 $\mathrm{m}^{2} / \mathrm{hab}$.), do Cambuci (15,62 $\mathrm{m}^{2} / \mathrm{hab}$.) e da Consolação (25,47 m²/hab.), destacados em azul na Tabela 02. Os distritos destacados em vermelho (Bela Vista, Liberdade, República e Santa Cecília) são os que registraram valores abaixo de $6 \mathrm{~m}^{2} / \mathrm{hab}$. 0 distrito da Sé apresenta um valor de 7,15 $\mathrm{m}^{2} / \mathrm{hab}$, destacado em amarelo.

O índice de $12 \mathrm{~m} 2$ de "área verde" por habitante, que tem sido usado como referência pela OMS, ONU, FAO e/ou PNUMA, poderia ser considerado o ideal por ser o mais veiculado. Porém, refere-se somente a parques de bairro e distritais ou setoriais, excluindo-se os parques de vizinhança, unidades de conservação, parques regionais e outros (CAVALHEIRO et al., 1999; NUCCI, 2008).

Visto que o valor de "área verde" por habitante não abrange toda a mancha de vegetação, pode-se considerar que a distribuição da vegetação entre os habitantes dos distritos do centro de São Paulo encontra-se muito aquém do esperado, com exceção dos três distritos citados anteriormente, pois o cálculo da CV/hab. engloba todas as áreas vegetadas.

Da mesma forma, faz-se uma análise também, a partir da Tabela 03, da discrepância existente entre o IDH distrital e a CV/hab. O distrito da Consolação é o único que apresenta IDH próximo ao valor considerado alto $(0,799)$ e está destacado em azul, da mesma forma que o da Sé, o único que registra um IDH considerado baixo $(0,498)$, destacado em vermelho. O distrito da Bela Vista, do Bom Retiro, do Cambuci, da Liberdade, da República e de Santa Cecília registram um IDH médio e são representados pela cor amarela, com valores de 0,692, 0,561, 0,534, 0,665, 0,534 e 0,654, respectivamente. 
Tabela 03: Dados demográficos e gradientes relativos ao ICV, à CV/hab. e ao IDH dos distritos da Subprefeitura da Sé

\begin{tabular}{|c|c|c|c|c|c|c|c|}
\hline DISTRITO & ÁREA (m²) & $\begin{array}{c}\text { HABITANTES } \\
\text { (2000) }\end{array}$ & $\begin{array}{c}\text { DENSIDADE } \\
\text { DEMOGRÁFIC } \\
\text { A (Hab./ha) }\end{array}$ & 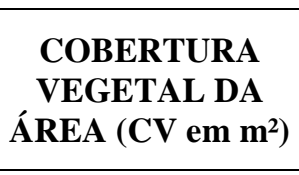 & $\begin{array}{c}\text { ÍNDICE DE } \\
\text { COBERTURA } \\
\text { VEGETAL } \\
(\text { ICV em \%) } \\
\end{array}$ & $\begin{array}{l}\text { CV/HAB. } \\
\text { (m²/hab.) }\end{array}$ & $\begin{array}{c}\text { IDH } \\
\text { (Fonte: SDTS, } \\
\text { 2002) }\end{array}$ \\
\hline $\begin{array}{c}\text { Bela Vista } \\
\text { (BUITRON; } \\
\text { FÁVERO, 2009) }\end{array}$ & 2.448 .000 & 63.190 & 258 & 221.000 & 9,02 & 3,49 & 0,692 \\
\hline $\begin{array}{c}\text { Bom Retiro } \\
\text { (MALDONADO; } \\
\text { FÁVERO, 2011) }\end{array}$ & 4.694 .500 & 26.598 & 56 & 455.900 & 9,71 & 17,14 & 0,561 \\
\hline $\begin{array}{c}\text { Cambuci } \\
\text { (GOMES; } \\
\text { FÁVERO, 2013) }\end{array}$ & 5.137 .600 & 28.717 & 55 & 448.700 & 8,64 & 15,62 & 0,534 \\
\hline $\begin{array}{c}\text { Consolação } \\
\text { (LOPES; } \\
\text { FÁVERO, 2006) }\end{array}$ & 5.163 .700 & 54.522 & 105 & 1.388 .950 & 26,89 & 25,47 & 0,799 \\
\hline $\begin{array}{c}\text { Liberdade } \\
\text { (LIANG, 2009) }\end{array}$ & 3.800 .000 & 61.875 & 162 & 307.200 & 8,08 & 4,96 & 0,665 \\
\hline $\begin{array}{c}\text { República } \\
\text { (ADAS; } \\
\text { FÁVERO, 2008) }\end{array}$ & 2.845 .000 & 47.718 & 167 & 249.300 & 8,76 & 5,22 & 0,534 \\
\hline $\begin{array}{c}\text { Santa Cecília } \\
\text { (NUCCI, 2008) }\end{array}$ & 3.600 .000 & 71.179 & 197 & 252.000 & 7,00 & 3,54 & 0,654 \\
\hline $\begin{array}{c}\text { Sé } \\
\text { (NUNES } \text { et al. } \\
\text { 2008) }\end{array}$ & 2.065 .500 & 20.115 & 97 & 144.000 & 6,97 & 7,15 & 0,498 \\
\hline
\end{tabular}

Fonte: FELIX (2014, p. 66). 
De acordo com SEMPLA (2006) e SDTS (2002), distritos que registram valores inferiores a 0,500 apresentam IDH baixo, os que registram valores entre 0,500 e 0,800 apresentam IDH médio e os que registram valores superiores a 0,800 apresentam IDH elevado, assim como dito anteriormente. Chediek et al. (2013) afirma que o ranking estimula formuladores e implementadores de políticas públicas a priorizar a melhoria de vida das pessoas em suas ações e decisões.

Fazendo uma relação entre IDH e CV/hab., observa-se claramente na Tabela 03 que, com exceção do distrito da Consolação, os três distritos que registram IDHs razoavelmente bons (Bela Vista, Liberdade e Santa Cecília), dentre os oito, são os que apresentam a CV/hab. mais baixa (vermelho). O distrito da Sé, o único com IDH abaixo de 0,500, não é o que apresenta a pior CV/hab. $\left(7,15 \mathrm{~m}^{2}\right)$. Da mesma forma, o distrito do Bom Retiro e do Cambuci, destacados em azul, apresentam boa distribuição de $\mathrm{CV} / \mathrm{hab}$., mas registram os valores referentes ao IDH mais baixos dentre os oito, quando relacionados com a cobertura vegetal.

Essa discrepância mostra-se típica da má distribuição dos investimentos públicos, que, segundo Winkler (2011), mantém a desigualdade do desenvolvimento entre os distritos da cidade de São Paulo. A falta de planejamento limita 0 aproveitamento dos benefícios trazidos pela vegetação às cidades (SERAFIM, 2008), sendo que a criação de parques urbanos e a simples arborização e ajardinamento passou a distinguir os bairros nobres dos populares, mais adensados e com menos áreas verdes circundantes (GUIMARÃES; DACANAL, 2006).

Os valores referentes ao IDH diferem entre si, pois o índice utiliza indicadores relativos à longevidade, educação e renda para fazer essa estimativa. Dessa forma, locais que apresentam ambiente saudável, com acesso às necessidades básicas ou com educação que permita o exercício da cidadania e o conhecimento de direitos e deveres da relação entre o Estado e o cidadão, tendem a registrar números elevados (CHEDIEK et al., 2013). Portanto, o cálculo para cada local varia de acordo com os valores estabelecidos para cada parâmetro, fazendo com que um distrito possa ter um alto, médio ou baixo desenvolvimento humano através das mudanças relativas a cada um, em determinado período de tempo.

O meio ambiente apresenta grande variação de acordo com o padrão da área e interação com outros fatores existentes em determinados locais e, portanto, não é passível de mensuração como 0 $\mathrm{IDH}$, pois este capta dados e mensura variáveis de forma simples, com atualização a cada dez anos e captação do progresso e resultados das políticas no curto prazo (CHEDIEK et al., 2013). Agregar grande número de variáveis torna-o complexo, limitando sua capacidade de ser usado como ferramenta para a sociedade estabelecer políticas públicas (OLIVEIRA, 2012). 
A qualidade de vida é um aspecto importante em análises e políticas de planejamento e de gestão e índices são construídos com o propósito de medir o bem-estar da população (MASSUDA; FAVORETTO, 2010). O IDH é muito utilizado para a realização dessa estimativa, já que considera características sociais, culturais e políticas (PNUD, 2012), as quais garantem, de acordo com Chediek et al. (2013), uma variedade de oportunidades, ampliando o bem-estar da população.

No entanto, considerar somente o IDH como referência para estimar uma boa qualidade de vida não é suficiente, pois, como afirma Herculano (2000), o real bem-estar deve envolver aspectos ambientais, visto que ter acesso somente à educação, aos serviços de saúde e à tecnologia contemporânea não garante uma qualidade de vida satisfatória. Os valores relativos ao IDH e à CV/hab. (Tabela 02), quando comparados, mostram essa contraposição de valores, como dito acima.

De acordo com Jesus et al. (2011), a redução da vegetação urbana possui um efeito negativo na qualidade socioambiental dos habitantes. Ao considerar a vegetação como atributo para a melhoria da qualidade de vida, através da qualidade ambiental, contribui-se para uma influência positiva desta no cotidiano da população em relação a impactos que geram desconforto e contribuem para um ambiente desagradável ao convívio humano. Assim, a vegetação funciona como obstáculo contra 0 vento, proteção da qualidade da água, fornecedora de alimentos, auxilia a filtração e regula a umidade do ar, estabiliza a temperatura, reduz o barulho, mantém a permeabilidade e fertilidade do solo, dentre outras funções (NUCCl, 2008).

Os índices de avaliação de qualidade de vida que não consideram devidamente a conservação da natureza nas áreas urbanas, como o IDH, não refletem adequadamente condições ambientais mínimas para uma boa qualidade de vida. 0 atributo "natureza" deve ser considerado na composição dos índices, pois favorece a qualidade ambiental para a população e, portanto, de acordo com Alvim (2011), as legislações devem considerar os aspectos ambientais para a implementação de políticas públicas, assim como a proposta feita pela Lei $n^{\circ} 13.580 / 2009$, para reduzir os impactos adversos, pois, sendo considerado um bem público, o meio ambiente é caracterizado como toda a circunvizinhança em que uma organização opera, incluindo ar, água, solo, recursos naturais, flora, fauna, seres humanos e suas inter-relações.

Segundo a Assembleia Legislativa do Estado de São Paulo (2009), a Lei n 13.580/2009 trouxe como proposta evitar questões presentes em áreas urbanas, como a formação de "ilhas de calor", poluição sonora e conservação da biodiversidade, para a recuperação e o desenvolvimento ambiental dos perímetros urbanos dos Municípios paulistas através de projetos de plantio de árvores, com 0 objetivo de atingir o "IAV" de $12 \mathrm{~m}^{2}$ por habitante. 
Os autores dos trabalhos referentes aos distritos da Subprefeitura da Sé verificaram a existência de vegetação desproporcional, com aglomeração em determinadas áreas e ausência em outras, diminuindo a acessibilidade e a possibilidade da maioria dos habitantes de usufruir desse atributo e conferindo qualidade ambiental distinta dentro do próprio distrito. Essa conformação mostrase típica de locais pavimentados, edificados e com processo intenso de urbanização, sem planejamento adequado para a conservação da vegetação. No entanto, as áreas verdes podem ser consideradas atributos para a melhoria de alguns impactos e podem indicar o grau da qualidade de vida da população urbana, de acordo com a distribuição da vegetação (JIM, 1989; SERAFIM, 2008).

Os estudos afirmam também que os distritos da Bela Vista, de Santa Cecília, da Liberdade e da República, que apresentam menor CV/hab., não contemplam a vegetação da forma como deveriam, como contribuição para melhoria da qualidade ambiental e de vida dos habitantes. De acordo com Aguiar (1996 apud SILVA, 2003), o excesso de áreas verdes é desejável e a desproporção dessas áreas com a densidade de ocupação não pode ser considerada, pois um ambiente saudável deve ser tido como garantia à qualidade de vida a todos os habitantes de determinado local. Eliers (1992 apud NUCCI, 2008; JIM, 1989) corrobora com esta ideia e afirma que a vegetação, quando disposta proporcionalmente, contribui para uma melhor ventilação e auxilia na remoção de poluentes, sendo a melhor técnica para prevenir ou reduzir os efeitos do clima nos centros urbanos.

De acordo com o caput do artigo 225 da Constituição Federal, todos têm o direito de acesso a um meio ambiente ecologicamente equilibrado e, este, sendo um bem de uso comum do povo, é essencial à qualidade de vida. Dessa forma, cabe ao poder público e à coletividade o dever da preservação, visto que a vegetação representa a qualidade estética, paisagística e ambiental da região (SILVA, 2003).

O planejamento relativo principalmente à arborização urbana é visto com descaso pelo setor público e, segundo Batista (2002), o verde urbano deve ser considerado prioridade como contribuinte para a melhoria da qualidade ambiental. Porém, como afirmam Loboda e De Angelis (2005), a fragmentação da paisagem é caracterizada por espaços privados preservados e espaços públicos abandonados e deteriorados, que são consequências, principalmente, da falta de recursos e do interesse, de quem planeja, pelos aspectos socioeconômicos.

A qualidade de vida é um conceito subjetivo e difícil de ser mensurado, portanto, é necessário que haja a compreensão da importância e dos benefícios da manutenção de um ambiente saudável, bem como ações locais, para que a população o enxergue como direito humano fundamental e condição necessária para a garantia de uma vida digna e sadia (MILARE, 2004 apud LISBOA; BARROS, 2008). 


\section{Conclusão}

A dimensão ambiental é considerada de forma limitada e indireta na composição da maioria dos índices socioeconômicos, como o IDH, abordado com maior ênfase neste trabalho por ser um dos mais utilizados na realização de avaliações da qualidade de vida da população. Esse índice não reflete, dentre outras questões, a qualidade de vida da população de forma adequada, visto que os aspectos ambientais não são considerados na elaboração do cálculo, por não apresentarem critérios e parâmetros objetivos devido ao conjunto de interações, levando à grande variação e a diferentes níveis de vulnerabilidade ao longo do tempo, de acordo com o padrão da área.

A vegetação é um atributo fundamental para a avaliação da qualidade de vida urbana, pois possibilita grande melhoria da qualidade ambiental de diversas maneiras. $E$, com 0 auxílio do mapeamento e quantificação da cobertura vegetal, é possível avaliar o ICV e fazer uma análise relativa à distribuição entre os habitantes, apontando, dessa forma, possíveis discrepâncias existentes entre locais próximos.

Apesar de alguns distritos apresentarem boa qualidade de vida, de acordo com o IDH, é de extrema importância que o centro de São Paulo seja tido como um dos locais prioritários para a execução de políticas públicas, como a proposta pela Lei $n^{\circ}$ 13.580/2009, com o objetivo de aumentar a quantidade de vegetação e amenizar os efeitos nocivos de sua ausência, visto que a maioria dos distritos apresenta qualidade ambiental insatisfatória, principalmente quando esta é relacionada à distribuição da cobertura vegetal entre os habitantes.

\section{Referências}

ADAS, M.; FÁVERO, O. Estudo da Cobertura Vegetal, na escala 1:10.000, do Subdistrito da República (Centro do Município de São Paulo/SP). Geografia. Ensino \& Pesquisa, São Paulo, v. 12, 2008. p. 2850-2863.

ALVIM, E. T. Políticas Públicas, sua Relação com a Riqueza Social e Cultural, e o Direito à Cidade. In: VII Congresso Nacional de Excelência em Gestão, 2011, Rio de Janeiro, RJ. Anais eletrônicos... Rio de Janeiro, RJ, 2011. Disponível em:

(http://www.excelenciaemgestao.org/Portals/2/documents/cneg7/anais/T11_0376_2148.pdf), data de acesso: 21 de abril de 2014.

ASSEMBLEIA LEGISLATIVA DO ESTADO DE SÃO PAULO. Lei № 13.580, de 24 de Julho de 2009. Diário Oficial do Estado de São Paulo, Poder Executivo, São Paulo, v. 119, n. 137, 2009, p.1. Disponível em: (http://www.al.sp.gov.br/norma/?id=157004), data de acesso: 24 de abril de 2014.

BATISTA, P. T. O Meio Ambiente, as cidades, as árvores urbanas e a SBAU. In: VI Congresso Nacional de Arborização Urbana, 2002, Goiânia, GO. Anais eletrônicos... Goiânia, GO, 2002. Disponível em: (http://sbau.org.br/materias_paulo_detarso.html), data de acesso: 24 de abril de 2014 .

BRAGA, T. M.; FREITAS, A. P. G.; DUARTE, G. S.; SOUZA, J. C. Índices de Sustentabilidade Municipal: O Desafio de Mensurar. Belo Horizonte: UFMG/Cedeplar, 2003. 22p. 
BUITRON L., FÁVERO, O. A. Estudo da Cobertura Vegetal do Subdistrito da Bela Vista (Centro de São Paulo/SP). In: XIII Simpósio Brasileiro de Geografia Física Aplicada, 2009, Viçosa, MG. Anais do XIIISBGFA... Viçosa, MG, 2009.

CAVALHEIRO, F.; DEL PICCHIA, P. C. D. Áreas Verdes: conceitos, objetivos e diretrizes para o planejamento. In: $1^{\circ}$ Congresso Brasileiro Sobre Arborização Urbana e $4^{\circ}$ Encontro Nacional Sobre Arborização Urbana, 1992, Vitória, ES. Anais eletrônicos... Vitória, ES, 1992. p. 29-38. Disponível em: (http://www.geografia.ufpr.br/laboratorios/labs/arquivos/CAVALHEIRO\%20et\%20al\%20(1992).pdf), data de acesso: 06 de abril de 2014.

CAVALHEIRO, F.; NUCCI, J. C.; GUZZO, P.; ROCHA, Y. T. Proposição de Terminologia para o Verde Urbano. Boletim Informativo da Sociedade Brasileira de Arborização Urbana (SBAU), Rio de Janeiro, a. 7, n 3, jul./ago./set. 1999. Disponível em:

(http://www.geografia.ufpr.br/laboratorios/labs/arquivos/CAVALHEIRO\%20et\%20al\%20(1999).pdf), data de acesso: 09 de abril de 2013.

CHEDIEK, J.; PERAL, A.; CHAVES, M. Atlas do Desenvolvimento Humano no Brasil 2013: o Índice de Desenvolvimento Humano Municipal Brasileiro. Brasília: PNUD, Ipea, FJP, 2013. 95p.

COSTA, M. J. P.; LUSTOSA, M. C. J. Mensuração do Desenvolvimento Socioeconômico e Ambiental. In: VII Encontro da Sociedade Brasileira de Economia Ecológica, 2007, Fortaleza, CE. Anais eletrônicos... Fortaleza, CE, 2007. 25p. Disponível em: (http://www.ecoeco.org.br/conteudo/publicacoes/

encontros/vii_en/mesa2/trabalhos/mensuracao_do_desenvolvimento.pdf), data de acesso: 04 de fevereiro de 2014.

DORADO, A. J.; ASSUNÇÃO, J. V.; RIBEIRO, H. Diagnóstico Ambiental no Município de Cubatão (SP) como Ferramenta de Avaliação dos Impactos sobre a Saúde Pública. Revista de Saúde, Meio Ambiente e Sustentabilidade, São Paulo, v. 6, n. 3, 2011. p. 58-73. Disponível em: (http://www.revistas.sp.senac.br/ index.php/ITF/article/view/187), data de acesso: 20 de fevereiro de 2014.

FELIX, C. S. Contribuição da Cobertura Vegetal Urbana para a Qualidade Ambiental e de Vida no Centro da Cidade de São Paulo. 2014. 86 f. Trabalho de Conclusão de Curso (Graduação em Ciências Biológicas) - Universidade Presbiteriana Mackenzie, São Paulo, 2014.

FIORE, E. G.; KUWAHARA, M. Y.; SILVA, R.; MACIEL, V. F. Proposta de Indicadores para a Qualidade de Vida no Município de São Paulo. Revista de Economia Mackenzie. São Paulo, v. 5, n. 5, 2007. p. 102-128.

GOMES, M. M. M., FÁVERO, O. A.. Mapeamento e Avaliação da Cobertura Vegetal do Distrito do Cambuci (Centro de São Paulo/SP). Periódico Técnico e Científico Cidades Verdes, v.1, 2013, p.174193.

Disponível

em:

(http://www.amigosdanatureza.org.br/publicacoes/index.php/cidades_verdes/article/view/415/441), data de acesso: 20 de fevereiro de 2014.

GUIMARÃES, S. T. L.; DACANAL, C. Arquitetar Para Viver, Educar Para Conservar: faces da qualidade ambiental e da qualidade de vida na conservação do meio ambiente. Climatologia e Estudos de Paisagem. Rio Claro, v. 1, n. 1/2, jul./dez. 2006. p. 20-39.

HERCULANO, S. C. A Qualidade de Vida e seus Indicadores. In: HERCULANO, Selene. PORTO, Marcelo Firpo de Souza. FREITAS, Carlos Machado. Qualidade de Vida e Riscos Ambientais. Niterói: Eduff, $2000, \quad$ p. 219-246. 2 Disponível (http://iris.ufsc.br/files/2014/11/reflexividade_na_sociedade_de_risco_conflitos_entre_leigos_e_peritos_ sobre_os_agrot\%c3\%93xicos1.pdf), data de acesso: 13 de fevereiro de 2014.

IBGE. Indicadores de Desenvolvimento Sustentável. Estudos \& Pesquisas. Rio de Janeiro, n. 9, 2012. Disponível em: (ftp://geoftp.ibge.gov.br/documentos/

recursos_naturais/indicadores_desenvolvimento_sustentavel/2012/ids2012.pdf), data de acesso: 23 de abril de 2014. 
IBGE. ONU e IBGE divulgam relatórios de população. Comunicação Social. 11 dez. 2001. Disponível em: (http://www.ibge.gov.br/home/presidencia/noticias/ 11122001onu.shtm), data de acesso: 03 de abril de 2013.

IBGE - SALA DE IMPRENSA. Censo 2010: população do Brasil é de 190.732 .694 pessoas. 29 nov. 2010. Disponível em: (http://saladeimprensa.ibge.gov.br/noticias?view=noticia\&id=1\&busca=1\&idnoticia=1766), data de acesso: 06 de abril de 2014.

INFOCIDADE - PREFEITURA DE SÃO PAULO. Temas. Disponível em: (http://infocidade.prefeitura.sp.gov.br/), data de acesso: 06 de abril de 2014.

JESUS, W. F.; SILVA, M. H.; BATISTA, L. F. A. Avaliação da Vegetação Urbana como Indicador da Qualidade Sócio-Ambiental da Cidade de Londrina-PR. In: XV Simpósio Brasileiro de Sensoriamento Remoto - SBSR, 2011, Curitiba, PR. Anais eletrônicos... Curitiba, PR, 2011. p. 1067. Disponível em: (http://www.dsr.inpe.br/sbsr2011/files/p0404.pdf), data de acesso: 24 de abril de 2014.

JIM, G. Y. Tree-Canopy Cover characteristics and urban development in Hong Kong. The Geographical Review, v. 79, n. 2. New York: American Geographical Society, 1989. p. 210-225.

LIANG, B. Estudo da Cobertura Vegetal do Subdistrito da Liberdade (Distrito Centro de São Paulo/SP). 2009. 50 f. Trabalho de Conclusão de Curso (Graduação em Ciências Biológicas) - Universidade Presbiteriana Mackenzie, São Paulo, 2009.

LISBOA, M.; BARROS, J. N. Direito Humano ao Meio Ambiente. Plataforma DhESCA Brasil. Curitiba, v. 2, $1^{a}$ ed., 2008. 44 p. Disponível em: (http://www.dhescbrasil.org.br), data de acesso: 24 de abril de 2014.

LOBODA, C. R.; DE ANGELIS, B. L. D. Áreas Verdes Públicas Urbanas: conceitos, usos e funções. Ambiência. Guarapuava, v. 1, n. 1, jan./jun. 2005. Disponível em: (http://200.201.10.18/index.php/ambiencia/article/view/157/185), data de acesso: 24 de abril de 2014. LOPES, B. J.; FÁVERO, O. A. The Vegetal Covering Study of the Consolação Area - São Paulo City, Brazil. In: IV Seminário Latinoamericano de Geografia Física, 2006, Maringá/PR. Anais... Maringá, PR, 2006.

LOUETTE, A. Indicadores de Nações: uma contribuição ao diálogo da sustentabilidade. São Paulo:

WHH, 2009. 111p. Disponível em:

(http://www.compendiosustentabilidade.com.br/2008/imagens/banco/arquivos/compendio_indicadores.

PDF), data de acesso: 23 de abril de 2014.

MAGLIO, I. C. A sustentabilidade ambiental no planejamento urbano do Município de São Paulo: 19712004. 2005. 421 f. Tese (Pós-Graduação em Saúde Pública) - Faculdade de Saúde Pública, Universidade de São Paulo, São Paulo, 2005.

MALDONADO, L. F., FÁVERO, O. A.. Mapeamento e Avaliação da Cobertura Vegetal do Distrito do Bom Retiro (Centro de São Paulo/SP). In: XIV Simpósio Brasileiro de Geografia Física Aplicada, 2011, Dourados/MS. Anais do XIVSBGFA, Dourados, MS, 2011. p.12.

MARTINS, A. R.; FERRAZ, F. T.; COSTA, M. M. Sustentabilidade Ambiental como Nova Dimensão do Índice de Desenvolvimento Humano dos Países. Revista do BNDES, Rio de Janeiro, v. 13, n. 26, 2006. p. 139-162.

MASSUDA, E. M.; FAVORETTO, C. K. Índice de Qualidade de Vida: aspectos objetivos e subjetivos. Revista Cesumar - Ciências Humanas e Sociais Aplicadas, Maringá, v. 15, n. 2., 2010. p. 405-408. Disponível

em:

(http://www.unicesumar.edu.br/pesquisa/periodicos/index.php/revcesumar/article/view/1701/1124), data de acesso: 10 de fevereiro de 2014.

NUCCI, J. C. Qualidade Ambiental e Adensamento Urbano - Um estudo de Ecologia e Planejamento da Paisagem aplicado ao distrito de Santa Cecília (MSP) - $2^{\mathrm{a}}$ ed. Curitiba: O Autor, 2008. 150p. Disponível em: (http://www.geografia.ufpr.br/laboratorios/labs/arquivos/qldade_amb_aden_urbano.pdf), data de acesso: 03 de abril de 2013. 
NUNES T. C. F.; LOBO, R. S. V.; MARQUES, T. C.; FÁVERO, O. A. Estudo da Cobertura Vegetal do Subdistrito da Sé, Centro de São Paulo/SP. Geografia. Ensino \& Pesquisa, v. 12, 2008. p. 1753-1766. OLIVEIRA, W. F. Índice de Desenvolvimento Humano e Pegada Ecológica: uma proposta de integração. In: XVI Encontro de Economia da Região Sul, 2012, Curitiba, PR. Anais eletrônicos... Curitiba, PR: UFRGS, 2012. 20p. Disponível em: (http://www.anpec.org.br/sul/2013/submissao/files_l/i2-9430aa81204616f26 da22cd7797044ec.pdf), data de acesso: 06 de abril de 2014.

PINA, S. A.; ALMEIDA, S. F., PINA, J. H. A. Uma Análise da Qualidade de Vida na Cidade de João PessoaPB frente à Questão Ambiental Mundial. Revista Caminhos de Geografia, Uberlândia, v. 11, n. 33, 2010. p. 168-178. (http://www.seer.ufu.br/index.php/caminhosdegeografia/article/viewFile/16142/9085), data de acesso: 14 de fevereiro de 2014.

PNUD. Desenvolvimento Humano e IDH. 2012. Disponível em: (http://www.pnud.org.br//DH/DH.aspx?indiceAccordion=0), data de acesso: 10 de fevereiro de 2014.

PNUMA. Um novo balanço para as Nações: UNU-IHDP e PNUMA lançam um índice de sustentabilidade que vai além do PIB. 17 jun. 2012. Disponível em: (http://www.pnuma.org.br/comunicados_detalhar.php?id_comunicados=213), data de acesso: 21 de abril de 2014.

SDTS. Desigualdade em São Paulo: o IDH. Prefeitura de São Paulo, ago. 2002. Disponível em: (www2.uol.com.br/aprendiz/n_noticias/imprescindivel/id150802.doc), data de acesso: 24 de abril de 2014 .

SEMPLA. Município em Mapas - Índices Sociais. Prefeitura de São Paulo, 2006. Disponível em: (http://www9.prefeitura.sp.gov.br/sempla/mm/), data de acesso: 24 de abril de 2014.

SERAFIM, A. R. M. D. B. R. O Verde na Cidade: análise da cobertura vegetal nos bairros do centro expandido da cidade do Recife - PE. In: IV Encontro Nacional da ANPPAS, 2008, Recife, PE. Anais eletrônicos... Recife, PE: UFPE, $2008 . \quad$ Disponível em: (http://www.anppas.org.br/encontro4/cd/ARQUIVOS/GT8-91-560-20080519075525.pdf), data de acesso: 06 de fevereiro de 2014.

SILVA, M. F. A desafetação de áreas verdes advindas de aprovação de loteamentos perante a tutela ambiental. Jus Navigandi. Teresina, ano 7, n. 113, 25 out. 2003. Disponível em: (http://www.mpba.mp.br/atuacao/ceama/material/

doutrinas/arborizacao/a_desafetacao_de_areas_verdes_advindas_de_aprovacao.pdf), data de acesso: 24 de abril de 2014.

VIALLI, A. Brasil desenvolve estudos para criar seu índice de "Felicidade Interna Bruta". 09 abr. 2012. Disponível em: (http://www1.folha.uol.com.br/ambiente/1073430-brasil-desenvolve-estudos-para-criarseu-indice-de-felicidade-interna-bruta.shtml), data de acesso: 21 de abril de 2014.

WINKLER, I. A Rede Nossa São Paulo e os Desafios da Mobilização por Cidades Mais Justas e Sustentáveis. Revista Brasileira de Casos de Ensino em Administração. v. 1, n. 1, jan./jun. 2011. Disponível em: (http://bibliotecadigital.fgv.br/ojs/index.php/gvcasos/article/view/3379/2175), data de acesso: 04 de fevereiro de 2014. 